\title{
Evaluation of local isolates of entomopathogenic nematodes for the management of black cutworm, Agrotis ipsilon Hufnagel (Lepidoptera: Noctuidae)
}

\author{
Ebubekir Yuksel ${ }^{*}$ (D) and Ramazan Canhilal
}

\begin{abstract}
The black cutworm, Agrotis ipsilon (Hufnagel) (Lepidoptera: Noctuidae) is considered to be one of the serious polyphagous pests that spend a large part of its life in the soil environment, where many microorganisms live including entomopathogenic nematodes (EPNs) (Rhabditida: Steinernematidae and Heterorhabditidae). EPNs have been long used for suppressing the soil-dwelling insects like cutworms and are successful biological control agent against $A$. ipsilon larvae. In the present study, the efficacy of local EPNs isolates against the fourth larval instar of $A$. ipsilon was evaluated at different concentrations $\left(10,25,50,100 \mathrm{IJs} /\right.$ larva/Petri dish and 25, 50, $100 \mathrm{IJs} / \mathrm{cm}^{2}$ soil) in two different experiment environments including filter papers in Petri dishes and soil in plastic containers under laboratory conditions at $25 \pm 1{ }^{\circ} \mathrm{C}$. Larval mortalities of $\mathrm{A}$. ipsilon were recorded first, second, third, and fourth day post inoculation where the mortality rates increased by increasing the concentrations. The maximum mortality rate (100\%) was reached within 2 days after inoculation, inoculating the Heterorhabditis bacteriophora FLH-4-H and $\mathrm{H}$. indica $216-\mathrm{H}$ isolates at concentrations of 50 and $100 \mathrm{IJs} / \mathrm{cm}^{2}$, in the plastic container experiment. The highest mortality rate (90\%) was obtained by Steinernema carpocapsae E76-S isolate at a concentration of $100 \mathrm{IJs} / \mathrm{larva} /$ Petri on the fourth day after inoculation, in the Petri dish experiment. The lethal concentration values $\left(L C_{50}\right.$ and $L C_{90}$ of the A. ipsilon larval population were $52 \mathrm{IJs}$ and $129 \mathrm{IJs}$, respectively, for S. feltiae E76-S isolate in the Petri dish tests. In the plastic container experiment, the lowest $L C_{50}$ and $L C_{90}$ values found to be $17 \mathrm{IJs}$ and $23 \mathrm{IJs}$, respectively, for $\mathrm{H}$. bacteriophora FLH-4-H isolate. The results showed that all indigenous EPN isolates had good potentials in the management of $A$. ipsilon.
\end{abstract}

Keywords: Agrotis ipsilon, Entomopathogenic nematodes, Steinernema, Heterorhabditis, Efficacy

\section{Background}

The black cutworm, Agrotis ipsilon (Hufnagel) (Lepidoptera: Noctuidae), is a major pest of over 30 economically important crops in many agricultural regions, which makes it survive nearly in every agroecosystem (Rings et al. 1975). A. ipsilon causes serious crop losses due to its wide host range including weeds, hidden lifestyle, feeding behavior, prolonged egg laying, and its ability for long-distance migration (Ya-Zhong 1992; Showers et al. 1993 and Capinera 2001). More than 80\% of the losses occur after reaching the fourth instar of larvae, which cuts

* Correspondence: ebubekiryuksel@erciyes.edu.tr Erciyes University, Kayseri, Turkey several plants overnight (Abdel-Gawaad and El-Shazli 1971 and Capinera 2001). Chemical control used against A. ipsilon larvae is often not effective and remains inadequate for the control of this pest because of its larval hiding behavior during the daylight hours and the resistance to most of the chemicals (Capinera 2001 and Takeda 2008). Therefore, the negative impact of the chemicals has led researchers to search for new control strategies (Laznik and Trdan 2012).

Biological control may fill the gap left by chemical pesticides and has a great potential in the suppression of agricultural pests. The entomopathogenic nematodes (EPNs), Steinernema spp. and Heterorhabditis spp. (Rhabditida: Steinernematidae and Heterorhabditidae), are among the 
most successful biological control agents that have distinctive features from other entomopathogens in many ways such as killing the host within $48 \mathrm{~h}$ with the help of the bacteria they carry in their intestines, providing long-lasting protection from any further pest infestation by settling into application area, and having infective juveniles (IJs) (a non-feeding stage), which have different foraging strategies (Gaugler 1981; Kaya and Gaugler 1993). EPNs are impactful microorganisms against insect pests in both soil and cryptic habitats. Satisfactory results also have been obtained by foliage applications depending on the new formulation techniques developed (Trdan et al. 2007; Laznik et al. 2010 and Ebssa and Koppenhöfer 2011). Many studies have been conducted in order to evaluate the virulence and control potential of entomopathogenic nematodes (EPNs) species or isolates against A. ipsilon larvae (Shamseldean et al. 1994; Mathasoliya et al. 2004; Fetoh et al. 2009; Seal et al. 2010; Ebssa and Koppenhöfer 2011 and Khattab and Azazy 2013).

The present study was carried out to evaluate the control potential of four native EPNs isolates and two different applications against $A$. ipsilon under laboratory conditions.

\section{Materials and methods Insect culture}

Healthy A. ipsilon larvae were collected from different corn, sugarbeet, and pumpkin fields, in the Mediterranean and Central Anatolia, Turkey, during May and June of 2017. A laboratory culture consisted of healthy larvae was established and maintained in a growth chamber at $25 \pm 1{ }^{\circ} \mathrm{C}$, R.H $60 \%$, and a photoperiod of 16:8 (L: D). Larvae were reared individually on lettuce in separate plastic cups $(63 \times 80 \mathrm{~mm})$ to avoid cannibalism and the lettuce cleaned with sterile water three times and dried before given to the larvae. Pupae were collected and placed in a glass jar for adult emergence and a cotton pad soaked in $10 \%$ honey solution were provided as food to adults and to support egg laying.

\section{Entomopathogenic nematodes isolates}

EPN isolates of Heterorhabditis bacteriophora FLH-4-H (Kayseri, Felahiye), H. indica 216-H (Kahramanmaraş, Afsin), Steinernema bicornotum MGZ-4 (Kayseri, Melikgazi), and S. carpocapsae E76-S (Kayseri, Tomarza) were obtained between years 2013 and 2017 from soil samples collected from Kayseri and Kahramanmaras provinces in the Central Anatolia and Mediterranean region of Turkey, respectively (Canhilal et al. 2016, 2017). EPN isolates were cultured on the last instar of Galleria mellonella L. (Lepidoptera: Pyralidae) at $25 \pm 1{ }^{\circ} \mathrm{C}$ and R.H. $60 \%$ under laboratory conditions. Harvested infective juveniles (IJs) were kept in a sterilized distilled water at 5$9{ }^{\circ} \mathrm{C}$ in the fridge until their use in the experiments
(Kaya and Stock 1997 and Ehlers 2001). Only 2-week old nematodes were used in the experiments.

\section{Pathogenicity test}

The virulence of four indigenous isolates against $A$. ipsilon larvae was evaluated in Petri dish arenas and plastic containers including soil in laboratory experiments. Isolates were tested against the fourth (L4) larval instar, the most susceptible to most EPN species (Ebssa and Koppenhöfer 2012). L4 instar larvae were detected by measuring their head capsule size and larval body length (Capinera 2001 and Gullan and Cranstone 2005). In order to avoid larval cannibalism, only one larva was placed in each Petri dish including two moist filter papers $(100 \times 15 \mathrm{~mm})$ and plastic containers $(63 \times 80 \mathrm{~mm})$ including $20 \mathrm{~g}$ of sterilized air-dried sand (application surface area $27 \mathrm{~cm}^{2}$ ). In order to prevent the larvae from undergoing starvation stress in the two experimental arenas, they were provided by a piece of cleaned lettuce every day (approximately $2 \mathrm{~cm}^{2}$ ). The arenas for the two experiments were incubated in the dark at $25 \pm 1{ }^{\circ} \mathrm{C}$, R.H. 60\%, and only distilled water was applied to the Petri dishes used as a control. Mortality rates at each experiment arena were recorded; first, second, third, and fourth day post treatment (DAT) and all the dead larvae were placed individually onto White traps, and the emergence of IJs from the dead body of the larvae was observed to confirm the nematode infection.

Each Petri dish was provided by $1 \mathrm{ml}$ of distilled water, containing different concentrations of IJs $(10,25,50$, and $100 \mathrm{IJs} /$ larva/Petri), and each nematode concentration was tested against ten $A$. ipsilon larvae and replicated four times. Petri dish experiment for each nematode isolate consisted of 160 Petri dishes (10 larvae $\times 4$ concentrations $\times 4$ replication).

Plastic containers of $180 \mathrm{ml}$ capacity were filled by $20 \mathrm{~g}$ of sterilized air-dried sand. Three nematode concentrations were used for the plastic container's arena: 25,50 , and $100 \mathrm{IJs} / \mathrm{cm}^{2}$ corresponding to 675, 1350, and 2700 IJs per plastic containers or larva, respectively. Plastic container experiment for each nematode isolate consisted of 120 plastic containers (10 larvae $\times 3$ concentrations $\times 4$ replication). The moisture content of each plastic container was $10 \%(w / w)$ after water-suspended nematodes were applied to the containers that included one healthy larva. Then, the cups were sealed with a lid allowing air exchange.

\section{Statistical analysis}

Statistical analysis was performed by SPSS (Version 11.0) statistical software package. Data was evaluated without being regulated by the Abbott formula since there was no mortality in control plates (Abbott, 1925). The significance of the main effects was determined by 
factorial analysis of variance (ANOVA). Mean values were separated using Tukey's multiple range test $(P<0.05)$. Estimation of the lethal concentration required to kill 50\% $\left(\mathrm{LC}_{50}\right)$ and $90 \%\left(\mathrm{LC}_{90}\right)$ of the pest population for each nematode isolates was calculated using Probit Analysis.

\section{Results and discussion}

The pathogenicity of the four local isolates of EPNs was tested against fourth larval instar of A. ipsilon under laboratory conditions. The results indicated that all isolates of nematodes tested were effective in controlling $A$. ipsilon and caused significant mortality rates. Mortality rates increased as the time of exposure increased. There was no mortality in control treatments for both experiment arenas.

In the Petri dish test, the mortality rate of $A$. ipsilon larvae was significantly affected by the nematode isolates $(\mathrm{N})$, IJ concentration $(\mathrm{C})$, and their interaction $(\mathrm{N} \times \mathrm{C})$ for second, third, and fourth days after treatment. Mortality rates were significantly affected by the only nematode isolates for the first day after treatment.

The highest mortality rate (90\%) was obtained by E76-S isolate at the highest applied concentration (100I)s/larva/Petri dish) in the Petri dish experiment for all exposure times. E76-S, 216-H, and MGZ-4-S isolates were found to be the most effective isolates at the concentration of $100 \mathrm{IJs} /$ larva for the third and fourth days after treatment. At the lowest concentration, isolate 216- $\mathrm{H}$ was recorded as the most virulent isolate among other isolates with $5,25,32$, and $40 \%$ mortality rates at the first, second, third, and fourth days after treatments, respectively. The nematode isolates E76-S and 216-H caused the highest A. ipsilon larval mortality (15 and $10 \%)$, respectively, at the concentration of 100 IJs/larva/ Petri, and no mortality was recorded by other tested isolates at all the application concentrations for the first day after treatment (Table 1).

In the plastic container experiment, the mean mortality rates of $A$. ipsilon larvae were significantly influenced by the nematode isolates $(\mathrm{N})$. IJ concentrations (C) were found to be statistically significant at the second day after treatment, while no significant effect was observed by the IJ concentrations at the other exposure times. Insignificant differences were noted statistically between mortality rates caused by the interaction between the nematode isolates and IJ concentrations $(\mathrm{N} \times \mathrm{C})$ for all the exposure times.

The results of the plastic container experiment showed that FLH-4-H was the most virulent isolate for all the applied concentrations and exposure times. The highest larval mortality rates were achieved by the FLH-4-H and 216-H isolates, starting with the second day after treatment. All isolates tested showed a great mortality rate at the lowest concentration of $25 \mathrm{IJs} / \mathrm{cm}^{2}$ in the second day of exposure time and the lowest and highest mortality rates were (80 and 100\%) caused by MGZ-4-S and FLH-4-H, respectively. Insignificant differences were found in mortality rates caused by the isolates tested and the concentrations used for the fourth day after treatment (Table 2).

The estimated $\mathrm{LC}_{50}$ values of the nematode isolates tested on the fourth instar A. ipsilon larvae ranged between 52 and 142 IJs at the Petri dish experiment and between 17 IJs and 24 IJs at the plastic container experiment at the second day after treatment. The lowest $\mathrm{LC}_{50}$ and $\mathrm{LC}_{90}$ values were achieved by the isolate E76-S (52 IJs) at the Petri dish experiment. In the plastic container experiment, the lowest $\mathrm{LC}_{50}$ and $\mathrm{LC}_{90}$ values were obtained by using the isolate FLH-4-H (17 IJs).

The pathogenicity of the four local Turkish EPN isolates, tested against fourth instar A. ipsilon larvae under laboratory conditions, showed that all of them caused significant mortality rates at both Petri dish and plastic container experiment arenas. In Petri dish experiment, S. carpocapsae E76-S isolate performed a more efficient control of the A. ipsilon larvae at 25, 50, and $100 \mathrm{IJs} /$ larva/Petri concentrations for all the exposure times, except at the first day. There was a positive relation between percent mortality and nematode concentration in both experiment arenas, which is in line with the studies of (Shoeb et al. 2006; Bélair et al. 2013; Mahmoud et al. 2016). In the previous Petri dish studies, $S$. carpocapsae was found more virulent than $H$. bacteriophora against the A. ipsilon larvae (Bélair et al. 2013 and Mahmoud et al. 2016).

In the Petri dish study, the commercial formulation of $S$. carpocapsae $(\mathrm{CSc}$ ) and some indigenous Canadian isolates were tested against the fifth instar of A. ipsilon larvae. CSc was found to be more effective than the other isolates tested (Bélair et al. 2013). CSc caused 37 and $48 \%$ mortality rates at the concentration of $50 \mathrm{IJs} /$ larva/Petri, after second and third days of exposure times, respectively, while the highest mortality rate among the indigenous isolates was $33 \%$, which is quite low compared to the obtained results. In the present study, mortality rates were found as 60 and $75 \%$ at the same concentration for the second and third days of exposure times, respectively. In the same study, the highest mortality rate for indigenous isolates $(94 \%)$ and CSc (98\%) was reached at 250 and 1000 IJs/larva/Petri concentrations after third day exposure time, respectively. The highest mortality rate for $S$. carpocapsae Turkish isolate E76-S (85\%) was reached at the concentration of $100 \mathrm{IJs} /$ larva/Petri after the third exposure time. Considering the obtaining of high mortality with low concentration, the virulence of Turkish indigenous isolate E76-S against $A$. ipsilon was very high as compared to results in the present study. 


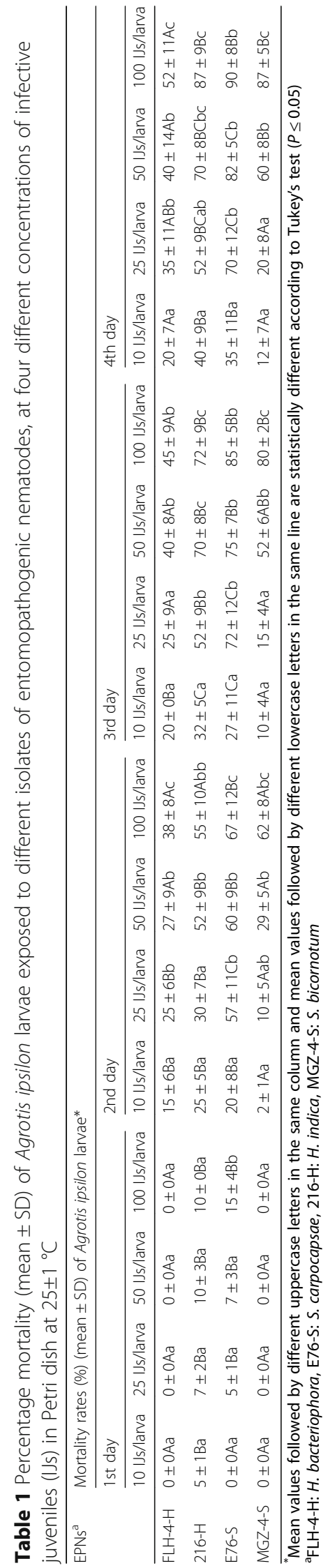




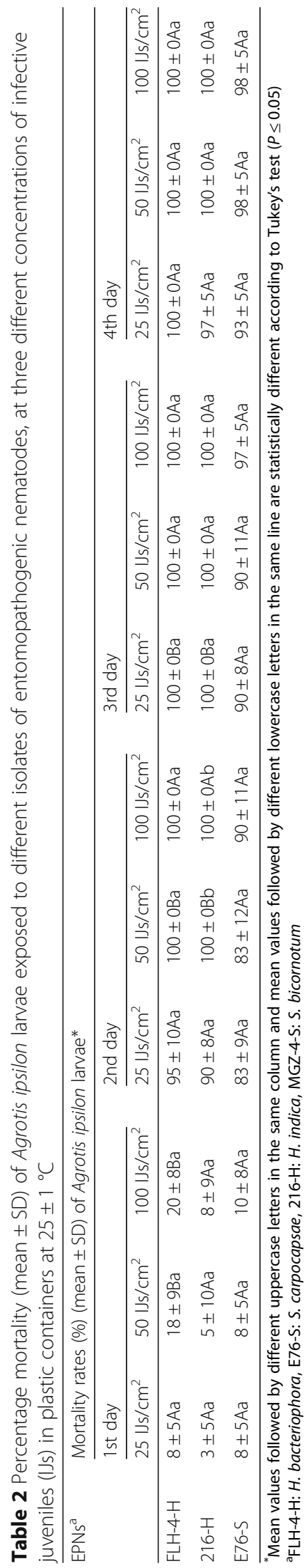


In another Petri dish study, EPNs were applied against the last instar larvae of $A$. ipsilon at seven concentrations $(0,20,40,80$, and $160 \mathrm{IJ} / \mathrm{ml})$ under laboratory conditions at $25 \pm 2{ }^{\circ} \mathrm{C}$ (Mahmoud et al. 2016). In this study, the maximum mortality rates for $S$. carpocapsae (100\%) and for H. bacteriophora (90\%) were reached at $80 \mathrm{IJ} / \mathrm{ml}$ and at $160 \mathrm{IJs} / \mathrm{ml}$ concentrations at the third day after treatment, respectively. In the present study, the highest mortality rates for S. carpocapsae (85\%) and for $H$. bacteriophora (45\%) at the third day after treatment were reached at $100 \mathrm{IJs} /$ larva/Petri concentration. Shoeb et al. (2006) investigated the efficacy of $S$. abbasi and $H$. bacteriophora against the fourth instar larvae of $A$. ipsilon in Petri dishes in the laboratory study at $27 \pm 1{ }^{\circ} \mathrm{C}$. They reported that $H$. bacteriophora caused 49, 53, and $73 \%$ mortality rates, respectively, at 25,50 , and 100 IJs/ larva in the second day after the treatment. Fetoh et al. (2009) evaluated the effectiveness of $S$. carpocapsae and $H$. bacteriophora against fourth instar A. ipsilon larvae at concentrations of 25, 50, $100 \mathrm{IJ} / \mathrm{ml}$ in Petri dish under laboratory conditions, and higher mortality rates were found compared to ours. Mortality rates, at the second day after treatment, were found as 70,85 , and $100 \%$ for $S$. carpocapsae and 80,90 , and $100 \%$ for H. bacteriophora at concentrations of 25,50 , and $100 \mathrm{IJs} / \mathrm{ml}$, respectively. In this study, mortality rates for the second day after treatment were 57,60 , and $65 \%$ for S. carpocapsae and 25,27 , and $38 \%$ for $H$. bacteriophora at 25, 50, and $100 \mathrm{IJ} / \mathrm{sl}$ concentrations, respectively. The reason of these differences in mortality rates can be attributed to the number of larvae used for the experiment. Shoeb et al. (2006), Fetoh et al. (2009), and Mahmoud et al. (2016) used a total of 15,25 , and 20 larvae in their study, respectively, whereas there were a total of 40 larvae for each concentration that belongs to the isolates in our study. The low number of samples can be misleading and does not represent the population exactly. In their study, small sample size might have led to high mortality rates. Another reason may be due to the different stages of the larvae used that the studies showed that fourth instar A. ipsilon larvae are the most susceptible stage to most EPN species (Ebssa and Koppenhöfer 2012). Mortality rates also might be affected by the foraging strategies of EPNs. S. carpocapsae is considered to be more effective than other species in controlling moving insects due to foraging behavior, and Petri dish might have created an environment that is more favorable to S. carpocapsae (Campbell and Gaugler 1993).

Although Petri dish experiment is a quick method to assess the effectiveness of EPNs, this technique can give false results due to the inability in simulating the field conditions. In order to determine the effectiveness of EPNs isolates in the soil, plastic container experiments have been conducted. Mortality rates have been found high in the soil environment, which is the natural habitat of EPNs, and the low mortality rate at the lowest concentration $\left(25 \mathrm{IJs} / \mathrm{cm}^{2}\right)$ after second day exposure time was $80 \%$ (MGZ-4-S), while the maximum mortality rate $(100 \%)$ was achieved at concentrations of 50 and 100 IJs/ $\mathrm{cm}^{2}$ (FLH-4-H and 216-H) after second day exposure time. Ebssa and Koppenhöfer (2012) evaluated the commercial formulations of $S$. carpocapsae and $H$. bacteriophora on different instars of $A$. ipsilon larvae in plastic cups of $30 \mathrm{ml}$ capacity, filled with soil, and the mortality rates at the second day exposure time were found 30 and $83 \%$ for $H$. bacteriophora and 18 and $55 \%$ for $S$. carpocapsae at concentrations of 30 and 100 IJs/larva, respectively. In the present study, mortality rates at the second day exposure time were 95 and $100 \%$ for $\mathrm{H}$. bacteriophora and 82 and $95 \%$ for S. carpocapsae at concentrations of 25 and $100 \mathrm{IJs} / \mathrm{cm}^{2}$, respectively. Mortality rates, especially at concentration $25 \mathrm{IJs} / \mathrm{cm}^{2}$, in our study was much higher than this study, most probably due to the different concentrations used for per larva. In another study, Hussaini et al. (2005), the potential of different EPNs on the last instar of $A$. ipsilon larvae was assessed in plastic containers, filled with soil at $20 \mathrm{IJs} / \mathrm{ml}$ and $180 \mathrm{IJs} / \mathrm{ml}$ at $25 \pm 1{ }^{\circ} \mathrm{C}$. $\mathrm{H}$. indica isolates showed more virulence than $S$. carpocapsae isolate and caused $100 \%$ mortality at the fourth day of exposure time and $S$. carpocapsae isolate was found as the least effective isolate against the last instar of $A$. ipsilon larvae, which is in line with our study. The maximum mortality rate $(100 \%)$ was reached on the fourth day after inoculation in this study. It was reached at the second day after inoculation in our study which means that these isolates were more pathogenic (Campbell and Gaugler 1993).

\section{Conclusion}

The study indicated that all the local isolates tested induced great mortality on the A. ipsilon larvae and gave promising results. Although heterorhabditid isolates appeared to be more virulent than steinernematid ones, generally, there were insignificant differences statistically between the EPN isolates in the plastic container experiment, and all the isolates caused higher mortality rates than at the Petri dish experiment. This study also showed that although Petri dish experiment is a quick method, it could give misleading results; therefore, it is necessary to conduct the experiments in both Petri dish and soil environments to evaluate EPNs effectiveness correctly.

\section{Abbreviations}

BCW: The black cutworm; C: Nematode concentration; DAT: Days after treatment; EPNs: Entomopathogenic nematodes; IJs: Infective Juveniles; L4: The fourth larval instars; $L C_{50}$ : The lethal concentration required to kill $50 \%$ of the pest population; $\mathrm{LC}_{90}$ : The lethal concentration required to kill $90 \%$ of the pest population; N: Nematode species; w/w: Weight per weight 


\section{Acknowledgements}

The authors thank Onur AKI and Merve UNAL for the support they gave in the laboratory studies.

\section{Funding}

This study was supported by TUBITAK-BIDEB 2209 student project.

\section{Availability of data and materials}

The datasets used and/or analyzed during the current study are available from the corresponding author on reasonable request.

\section{Authors' contributions}

$\mathrm{EY}$ and RC have planned the outline of this research and designed the methodology together. EY carried out the laboratory studies and drafted the manuscript. Both authors read and approved the final manuscript.

\section{Ethics approval and consent to participate}

Not applicable.

\section{Consent for publication}

Not applicable.

\section{Competing interests}

The authors declare that they have no competing interests.

\section{Publisher's Note}

Springer Nature remains neutral with regard to jurisdictional claims in published maps and institutional affiliations.

Received: 17 July 2018 Accepted: 4 October 2018

Published online: 16 October 2018

\section{References}

Abdel-Gawaad AA, El-Shazli AY (1971) Studies on the common cutworm Agrotis ipsilon Rott. I. Life cycle and habits. Z Angew Entomol 68:409-412

Abbott WS (1925) A method of computing the effectiveness of an insecticide. J Econ Entomol 18:265-267.

Bélair G, Simard L, Dionne J (2013) Canadian entomopathogenic nematode isolates: virulence against black cutworm (Lepidoptera: Noctuidae). Phytoprotection 93(1):43-46

Campbell JF, Gaugler R (1993) Nictation behaviour and its ecological implications in the host search strategies of entomopathogenic nematodes (Heterorhabditidae and Steinernematidae). Behaviour 126(3):155-169

Canhilal R, Waeyenberge L, Toktay H, Bozbuga R, Cetintas R, Imren M (2016) Distribution of Steinernematids and Heterorhabditids (Rhabditida: Steinernematidae and Heterorhabditidae) in the Southern Anatolia region of Turkey. Egypt J Biol Pest Co 26(4):5

Canhilal R, Waeyenberge L, Yuksel E, Koca AS, Deniz Y, Imren M (2017) Assessment of the natural presence of entomopathogenic nematodes in Kayseri soils, Turkey. Egypt J Biol Pest Co 27(2):4

Capinera JL (2001) Handbook of vegetable pests. Academic Press, New York, p 729

Ebssa L, Koppenhöfer AM (2011) Efficacy and persistence of entomopathogenic nematodes for black cutworm control in turf grass. Biocontrol Sci Techn 21(7):779-796

Ebssa L, Koppenhöfer AM (2012) Entomopathogenic nematodes for the management of Agrotis ipsilon: effect of instar, nematode species and nematode production method. Pest Manag Sci 68(6):947-957

Ehlers R (2001) Mass production of entomopathogenic nematodes for plant protection. Appl Microb Technol 56:623-633

Fetoh BA, Amani SK, Thoraia FKE (2009) Combined effect of entomopathogenic nematodes and biopesticides to control the greasy cutworm, Agrotis ipsilon (Hufn.) in the strawberry fields. Egypt Acad J Biology Sci 2(1):227-236

Gaugler R (1981) Biological control potential of neoaplectanid nematodes. J Nematol 13:241-149

Gullan PJ, Cranstone PS (2005) The insects, an outline of entomology, 3rd edn. Blackwell Publishing, Oxford, p 505

Hussaini SS, Shakeela V, Dar MH (2005) Influence of temperature on infectivity of entomopathogenic nematodes against black cutworm, Agrotis ipsilon (Hufnagel) and greater wax moth, Galleria mellonella (Linnaeus) larvae. J Biol Control 19(1):51-58
Kaya HK, Gaugler R (1993) Entomopathogenic nematodes. Annu Rev Entomol 38: $181-206$

Kaya HK, Stock SP (1997) Techniques in insect nematology. In: Lawrence AL (ed) Manual of techniques in insect pathology. Academic Press, Washington, pp 281-324

Khattab M, Azazy AM (2013) Efficacy of entomopathogenic nematodes as bait formulations for controlling the black cutworm Agrotis ipsilon (Hufnagel) (Lepidoptera: Noctuidae). Egypt J Biol Pest Co 23(2):255

Laznik Ž, Tóth T, Lakatos T, Vidrih M, Trdan S (2010) Control of the Colorado potato beetle (Leptinotarsa decemlineata [say]) on potato under field conditions: a comparison of the efficacy of foliar application of two strains of Steinernema feltiae (Filipjev) and spraying with thiametoxam. JPDP 117(3): 129-135

Laznik Z, Trdan S (2012) Entomopathogenic nematodes (Nematoda: Rhabditida) in Slovenia: from tabula rasa to implementation into crop production systems. In: Perveen F (ed) Insecticides-Advances in Integrated Pest Management. InTech, London

Mahmoud MF, Mahfouz HM, KM M (2016) Compatibility of entomopathogenic nematodes with neonicotinoids and Azadirachtin insecticides for controlling the black cutworm, Agrotis ipsilon (Hufnagel) in canola plants. IJRES 2(1):11-18

Mathasoliya JB, Maghodia AB, Vyas RV (2004) Efficacy of Steinernema riobrave against Agrotis ipsilon Hufnagel (Lepidoptera: Noctuidae) on potato. Indian J Nematol 34(2):177-179

Rings RW, Arnold FJ, Johnson BA (1975) Host range of the black cutworm on vegetables: a bibliography. ESA Bull 21(4):229-234

Seal DR, Jha VK, Liu TX (2010) Potential of various strains of entomopathogenic nematodes in combination with insecticides for suppression of black cutworm, Agrotis ipsilon (Lepidoptera: Noctuidae). Ann P1 Protec Sci 18(2): 293-300

Shamseldean MM, Abd El-Gawad MM, El-Bishry MH (1994) Comparative infectivity of native heterorhabited nematodes and the potential use of one isolate against some economically important pests in Egypt. Egypt J Biol Pest Cont 4(2):133-139

Shoeb MA, Atalla FA, Matar AM (2006) Pathogenicity of the entomopathogenic nematodes; Steinernema abbasi and Heterorhabditis bacteriophora to certain economic insect pests. Egypt J Biol Pest Co 16(1/2):99-102

Showers WB, Keaster AJ, Raulston JR, Hendrix WH, Derrick ME, McCorcle MD, Goodenough JL (1993) Mechanism of southward migration of a noctuid moth [Agrotis ipsilon (Hufnagel)]: a complete migrant. Ecology 74(8):2303-2314

Takeda M (2008) Current research of pest insects of vegetables in last decade. Annual Rep Kansai Plant Protect 50:39-44

Trdan S, Znidarcic D, Vidrih M (2007) Control of Frankliniella occidentalis on glasshouse-grown cucumbers: an efficacy comparison of foliar application of Steinernema feltiae and spraying with abamectin. Russ J Nematol 15(1):25

Ya-Zhong J (1992) The flight activity of the black cutworm moth [J]. Acta Entomol Sin 1:009

\section{Submit your manuscript to a SpringerOpen ${ }^{\circ}$ journal and benefit from:}

- Convenient online submission

- Rigorous peer review

- Open access: articles freely available online

High visibility within the field

- Retaining the copyright to your article

Submit your next manuscript at $\boldsymbol{\text { springeropen.com }}$ 